\title{
Surface Structures of Clean and Sulfur-Treated GaP(111)A Studied Using AES, LEED, and STM*
}

\author{
S. Itagaki, M. Shimomura, N. Sanada, and Y. Fukuda ${ }^{\dagger}$ \\ Research Institute of Electronics, Shizuoka University, Johoku 3-5-1, 432-8011 Japan \\ (Received 2 June 2008; Accepted 11 March 2009; Published 4 April 2009)
}

\begin{abstract}
Surface structures of clean and sulfur-treated $\mathrm{GaP}(111) \mathrm{A}$ have been studied by Auger electron spectroscopy (AES), low-energy electron diffraction (LEED), and scanning tunneling microscopy (STM). A GaP(111)A surface is reconstructed into a $2 \times 2$ structure by Ar ion sputtering and annealing at $450^{\circ} \mathrm{C}$. The $2 \times 2$ structure is for the first time imaged by STM. A surface structure model for the structure is discussed in terms of the cation-vacancy model. The sulfur-treated surface shows a $1 \times 1$ LEED pattern and the relative AES intensity of sulfur remains constant between $200-500^{\circ} \mathrm{C}$. The coverage of sulfur on the $\mathrm{GaP}(111) \mathrm{A}$ surface is estimated to be about 0.82 monolayers. The sulfur is desorbed at about $550^{\circ} \mathrm{C}$ where the LEED pattern was changed into a facet-like one. The different surface reconstructions $(1 \times 1-\mathrm{S}$ and $2 \times 2-\mathrm{S})$ on sulfur-treated III-V compound semiconductor $(111) \mathrm{A}$ surfaces are discussed in terms of the bond strength. [DOI: 10.1380/ejssnt.2009.213]
\end{abstract}

Keywords: Surface structures; Gallium phosphide (GaP); Scanning tunneling microscope (STM); Low energy electron diffraction (LEED); Auger electron spectroscopy (AES)

\section{INTRODUCTION}

The $\{111\}$ surfaces of III-V compound semiconductors have been widely studied using low-energy electron diffraction (LEED), scanning tunneling microscopy (STM), and photoemission spectroscopy (PES) [1]. The (111)A surfaces terminated by cation were reported to be reconstructed into a $2 \times 2$ structure [1]. The surface structure model for the $2 \times 2$ surface, the cation-vacancy model, is recognized to be applicable for the surface annealed at higher temperature [2], although the $\sqrt{3} \times \sqrt{3}$ R30 ${ }^{\circ}$ structure covered with phosphorus trimer was found for the $\operatorname{InP}(111) \mathrm{A}$ surface annealed at lower temperature [3]. The cation-vacancy model was supported by the results of a calculation [4] and STM measurement [5]. For the $\mathrm{GaP}(111)$ A surface, however, only a few studies using LEED were reported, where a $2 \times 2$ LEED pattern was found $[6,7]$ and a LEED intensity analysis supported the cation-vacancy model.

The structure of sulfur-treated III-V compound semiconductor (111) surfaces is also interesting from the view point of passivation of the surfaces [8-10]. The $1 \times 1$ $\mathrm{S}$ structure was reported for the GaAs(111)A surface treated by sulfur followed by annealing [11]. The sulfur was found to be adsorbed on Ga atoms exposed to the surface [12].

On the other hand, the $2 \times 2-\mathrm{S}$ structure was found on the (111)A surfaces of InAs [13-15], InP [16], and InSb [17] treated by sulfur followed by annealing. A plausible model was presented based on the results of STM and photoelectron diffraction (PED) $[14,16]$ : the "Invacancy and sulfur bonded to In in threefold coordination" model. It should be pointed out that the different surface reconstructions $(1 \times 1-\mathrm{S}$ and $2 \times 2-\mathrm{S}$ structures $)$ occur on the (111)A surfaces containing Ga and In atoms, respectively. Therefore, it is very interesting whether the

\footnotetext{
* This paper was presented at the 14th International Conference on Solid Films and Surfaces (ICSFS-14), Trinity College Dublin, Ireland, 29 June - 4 July, 2008.

†Corresponding author: royfuku@rie.shizuoka.ac.jp
}

$\mathrm{GaP}(111) \mathrm{A}$ surface is reconstructed into the $1 \times 1-\mathrm{S}$ structure or not.

In this paper the result on the clean and sulfur-treated GaP(111)A surfaces studied using Auger electron spectroscopy (AES), LEED, and STM are described. The surface structure is discussed in terms of the cation-vacancy model and the bond strength for the clean and sulfurtreated surfaces, respectively.

\section{EXPERIMENTAL}

An n-GaP(111)A sample was dipped in an $\left(\mathrm{NH}_{4}\right)_{2} \mathrm{~S}_{x}$ solution for about $30 \mathrm{~min}$ at RT to etch the surface oxide. It was rinsed by deionized water and introduced in an ultra-high vacuum chamber $\left(10^{-10}\right.$ Torr $)$ after drying. The sample was cleaned by iterations of Ar ion sputtering $(400 \mathrm{eV})$ and annealing at $200-550^{\circ} \mathrm{C}$. The sulfur-treated surface was prepared by annealing the sample after the sulfur-treatment with the $\left(\mathrm{NH}_{4}\right)_{2} \mathrm{~S}_{x}$ solution. Temperature of the sample was measured by an infra-red pyrometer.

Cleanness and structures of the surfaces were monitored by AES and LEED, respectively. An AES measurement was first carried out for the GaP (110) surface obtained by cleaving the (001) sample in the chamber to know the intensity ratio of $\mathrm{Ga}$ to $\mathrm{P}$ for the surface with the equal amount of both the atoms. Then the AES measurements were performed on the (111)A surface annealed at various temperatures. STM measurements were carried out using JSTM-4500XT (JEOL). The STM images were observed at a bias voltage, $-3.00 \mathrm{~V}$ and tunneling currents, 0.20 nA. However, empty states could not be imaged.

\section{RESULTS AND DISCUSSION}

The GaP(111)A surface was sputtered by Ar ion at 400 eV until the AES lines of S $L M M, \mathrm{C} K L L$, and $\mathrm{O} K L L$ disappear and then annealed at $200-500^{\circ} \mathrm{C}$. AES intensity ratios of the $\mathrm{Ga} M M M$ to $\mathrm{P} L M M$ lines at various annealing temperatures are shown in Fig. 1. Since the ratio, 0.15 , corresponds to the equal amount of $\mathrm{Ga}$ and $\mathrm{P}$, the 


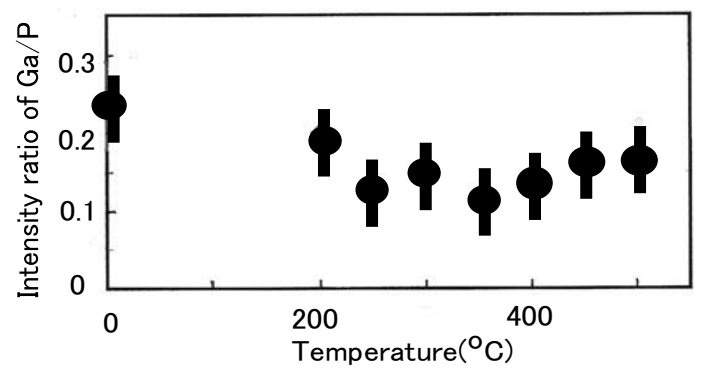

FIG. 1: AES intensity ratios of the Ga $M M M$ to $\mathrm{P} L M M$ lines at various annealing temperatures.
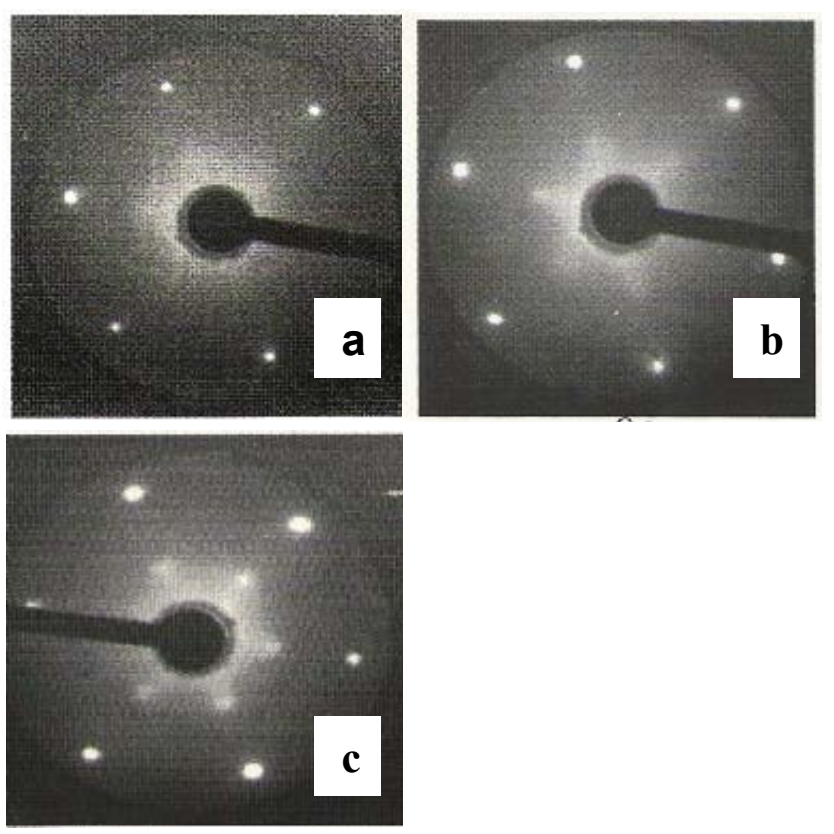

FIG. 2: LEED patterns for the $\mathrm{GaP}(111)$ A surface sputtered by $\mathrm{Ar}$ ion $(400 \mathrm{eV})$, followed by annealing at 390 (a), 420 (b), and $450(\mathrm{c})^{\circ} \mathrm{C}$.

surface sputtered is enriched by Ga. Upon annealing the sample the amount of $\mathrm{Ga}$ is decreased up to $350^{\circ} \mathrm{C}$ and increased above it. The $\mathrm{Ga}$ is again enriched on the surface region upon annealing at $450^{\circ} \mathrm{C}$. The decrease and increase in the intensity ratios upon annealing are due to segregation of phosphorus from the bulk and desorption of it from the surface, respectively [18]. The tendency in the decrease and increase upon annealing was reproducible.

Changes in LEED patters for the surface annealed at 390, 420, and $450^{\circ} \mathrm{C}$ are displayed in Fig. 2. The clear $1 \times 1$ pattern was observed at $390^{\circ} \mathrm{C}$ and $\times 2$ spots begin to appear at $420^{\circ} \mathrm{C}$. The clearest pattern is found at $450^{\circ} \mathrm{C}$ and annealing at $550^{\circ} \mathrm{C}$ led to the facet-like patterns. The AES result suggests that the surface with the $\times 2$ spots is enriched by $\mathrm{Ga}$ atoms.

STM filled state images of the $2 \times 2$ surface were observed at a sample bias, $-3.00 \mathrm{~V}$ and tunneling currents, $0.20 \mathrm{nA}$. Many small areas with ordered protrusions were found. The typical image (image size: $4.0 \times 8.0 \mathrm{~nm}^{2}$ ) and line profiles (along A-A' and B-B') are shown in Fig. 3. The protrusions are found to be arranged along the [01 $\overline{1}]$ (a)

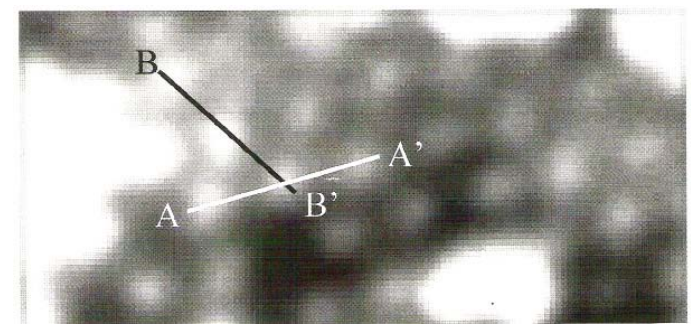

(b)
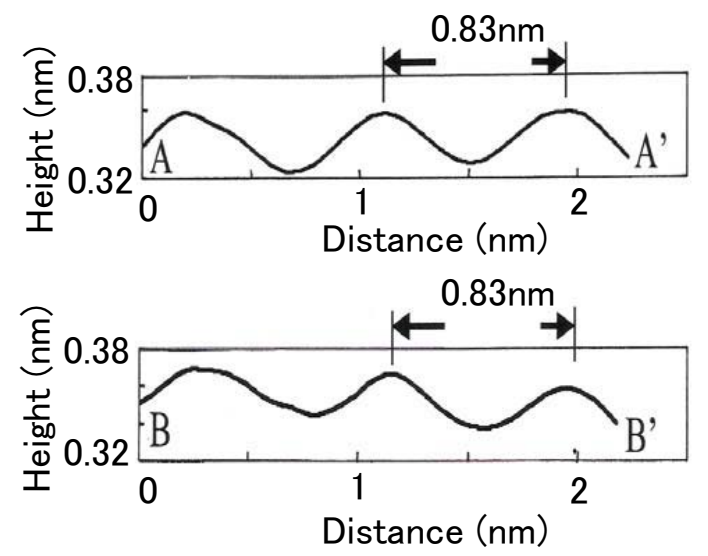

FIG. 3: (a) STM filled state images for the $\operatorname{GaP}(111) \mathrm{A}-2 \times 2$ surface (image size: $4.0 \times 8.0 \mathrm{~nm}^{2}$ ). Bias voltage, $-3.00 \mathrm{~V}$ and tunneling currents: $0.20 \mathrm{nA}$. (b) The line profiles for A-A' and B-B'.

$\left(\mathrm{A}-\mathrm{A}^{\prime}\right)$ and $[10 \overline{1}]$ (B-B') directions. The distance between the protrusions is about $0.83 \mathrm{~nm}$ for A-A' and B-B' [Fig. 3(b)], which implies that the protrusion distance corresponds to about two times the surface lattice constant. This is consistent with the LEED result in Fig. 2. We could not observe the STM empty state images.

The STM images for the $\operatorname{GaAs}(111) \mathrm{A}-2 \times 2$ surface were presented [9, 19]. The empty state images reflecting empty dangling bonds on Ga atoms showed the protrusions with separation by about $0.4 \mathrm{~nm}$ along the [011] direction and the dark feature due to the absence of every second Ga atom (vacancy) in the direction [19]. This supported the Ga-vacancy model [2].

On the other hand, the feature of the filled state images reflecting the filled dangling bonds on As atoms was different from that of the empty state images. The group of three atoms surrounding the Ga vacancy was closer together (shifted to the vacancy) than the three surrounding Ga atoms. This result was predicted by both the results of theory [4] and LEED [2] in accompanying with a downward relaxation of the Ga atoms. These movements allow the $\mathrm{Ga}$ atoms to bond close to their $\mathrm{sp}^{2}$ configuration, and for the As atoms around the vacancy to attain a near $\mathrm{sp}^{3}$ configuration. The empty and filled state images along with the theory and LEED analysis also supported the Ga-vacancy model.

For the $\operatorname{GaP}(111) \mathrm{A}-2 \times 2$ surface found here, three protrusions, which were observed on the $\operatorname{GaAs}(111) \mathrm{A}-[19]$ and $\operatorname{InSb}(111) \mathrm{A}-2 \times 2$ [20] surfaces, are not found in the filled state images. This suggests that the images are not resolved in the atomic level. Therefore, one protrusion 


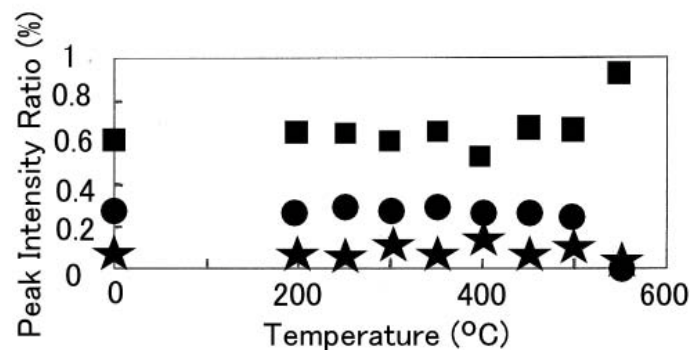

FIG. 4: Relative AES intensities (a peak intensity / summed all intensity) for the sulfur-treated $\mathrm{GaP}(111) \mathrm{A}$ surface at various annealing temperatures. Squares, circles, and stars correspond to $\mathrm{P}, \mathrm{Ga}$, and $\mathrm{S}$, respectively.

observed here would image three $\mathrm{P}$ atoms with filled dangling bond surrounding the Ga vacancy site. The size of the observed protrusion is about $0.40 \mathrm{~nm}$. On the other hand, the group of the three $\mathrm{P}$ atoms surrounding the Ga vacancy is about $0.53 \mathrm{~nm}$ in size if any relaxations do not occur. According to the cation-vacancy model for the $2 \times 2$ surface, the $\mathrm{P}$ atoms are shifted to the cation-vacancy site [7]. Taking account of the shift, one protrusion observed here would correspond to the group of the three $\mathrm{P}$ atoms. Our STM result supports the cation-vacancy model.

Several works on the STM measurements for the $\mathrm{GaP}(001)-2 \times 4$ surface were reported [21-25]. However, the clear images resolved atomically were hardly obtained except for one work [22] in which they were found at very small area $[24,25]$. It should be pointed out that no STM empty state images for $n$-GaP were reported so far. The difficulty of obtaining the clear images for the surface might originate from the wide band gap.

Figure 4 shows changes in AES relative peak intensity for the sulfur-treated $\mathrm{GaP}(111) \mathrm{A}$ surface at various annealing temperatures. The sulfur and phosphorus intensities remain almost constant between $\mathrm{RT}$ and $500^{\circ} \mathrm{C}$. Upon annealing at $550^{\circ} \mathrm{C}$ the sulfur disappears and the phosphorus increases in intensity.

The attenuation length of sulfur AES electrons with 150 $\mathrm{eV}$ in $\mathrm{GaP}$ can be calculated to be about $1.34 \mathrm{~nm}$ using the Seah-Dench equation [26]. We estimate a thickness of the sulfur layer to be about $0.30 \mathrm{~nm}$ using the overlayer model [27] and the following parameters: the attenuation length $(1.34 \mathrm{~nm})$, the sensitivity factor for sulfur $(0.80)$ and phosphorus (0.55) [28], and AES intensity at $500^{\circ} \mathrm{C}$ of sulfur (25.0) and phosphorus (67.5) in Fig. 4. On the other hand, since the diameter of a sulfur ion is $0.37 \mathrm{~nm}$, the thickness of the sulfur layer is estimated to be about 0.82 monolayers. The above result and argument suggest that sulfur is bonded to gallium atom on the $\mathrm{GaP}(111) \mathrm{A}$ surface, forming about 0.82 monolayers and leading to formation of the $1 \times 1$ surface structure (observed by LEED described later) in the wide area on the surface.

The LEED patterns for the surface annealed at 250 and $500^{\circ} \mathrm{C}$ are shown in Fig. 5. A weak $1 \times 1$ pattern was observed between 200 and $450^{\circ} \mathrm{C}$. It becomes intense at $500^{\circ} \mathrm{C}$ although the background intensity is high. This suggests that the $1 \times 1-\mathrm{S}$ structure is formed because sulfur remains on the surface and the coverage of sulfur is
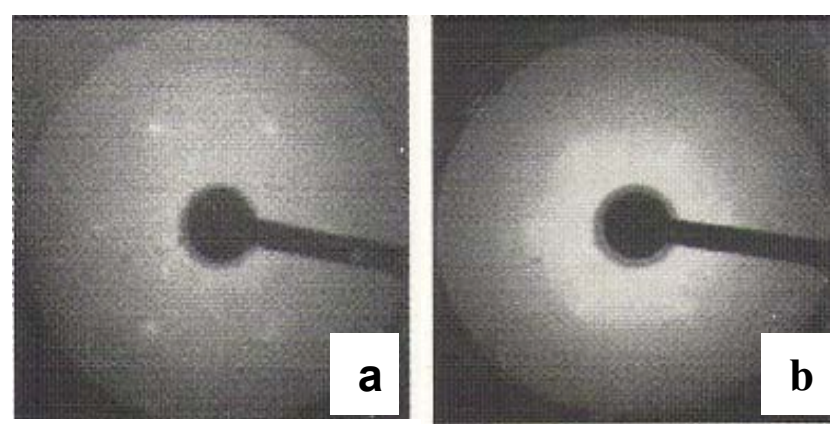

FIG. 5: LEED patterns for the sulfur-treated GaP(111)A surface annealed at 250 (a) and $500{ }^{\circ} \mathrm{C}(\mathrm{b})$.

about 0.82 monolayers. The little lack of sulfur for the one monolayer may lead to the LEED patter with high background. The facet-like pattern appeared at $550^{\circ} \mathrm{C}$, where the sulfur disappears on the surface, being in good agreement with the result on the clean surface.

On the analogy of the result [12] on GaAs(111)A surface adsorbed by sulfur and based on the above sulfur coverage, the $\mathrm{GaP}(111) \mathrm{A}$ surface would be terminated by sulfur, resulting in formation of the $1 \times 1$ LEED pattern. The $1 \times 1$ pattern is observed between 200 and $500^{\circ} \mathrm{C}$ and it become intense at $500^{\circ} \mathrm{C}$, indicating that the $1 \times 1$ structure at $500^{\circ} \mathrm{C}$ is more ordered than the other temperature. We suggest that this intense $1 \times 1$ structure is not due to formation of the ordered bulk structure because the ordered $\mathrm{GaP}(111) \mathrm{A}$ surface is formed at $390^{\circ} \mathrm{C}$ as observed in Fig. 2.

It was reported that the $1 \times 1-\mathrm{S}$ structure is formed on the sulfur-treated $\operatorname{GaAs}(111) \mathrm{A}$ surface [11], which is in agreement with the result in the present work. On the other hand, the $2 \times 2$-S structure was found for the sulfurtreated (111)A surfaces of InP [16], InAs [13-15], and InSb [17]. The difference in the sulfur-adsorbed surface structure depending upon the substrates is very interesting. The bond strength between Ga and anions (As, P, and $\mathrm{Sb}$ ) is stronger than that between In and anions (As, $\mathrm{P}$, and $\mathrm{Sb}$ ) [29], respectively. This suggests that sulfur can more easily break the In-anion bonds than those of Gaanion, resulting in the formation of the $2 \times 2-\mathrm{S}$ structure with bonding to In atoms in threefold coordination on the (111) surfaces of InAs [12-15], InP [16], and InSb [17]. On the other hand, sulfur is adsorbed on the Ga atom exposed to the surface without breaking the Ga-As and Ga-P bonds, leading to formation of the $1 \times 1-\mathrm{S}$ structure $[11,12]$. The above discussion is very simplified. The total energy calculation for the sulfur-treated surfaces is required to understand the stability of the $1 \times 1-\mathrm{S}$ and $2 \times 2$-S reconstructions.

\section{SUMMARY}

The surface structures of the clean and sulfur-treated GaP(111)A samples have been studied by AES, LEED, and STM. The GaP(111)A surface is found to be reconstructed into the $2 \times 2$ structure by Ar ion sputtering and annealing at $450^{\circ} \mathrm{C}$. The $\mathrm{GaP}(111) \mathrm{A}-2 \times 2$ structure is for 
the first time imaged by STM. The protrusions are arranged in the $[01 \overline{1}]$ and $[10 \overline{1}]$ directions with the distance about $0.83 \mathrm{~nm}$ that corresponds to about two times the surface lattice constant. The surface structure model for the $2 \times 2$ surface is discussed in terms of the cation-vacancy model. The sulfur-treated surface shows the weak $1 \times 1$ LEED pattern and the LEED intensity is found to be highest for the surface annealed at $500^{\circ} \mathrm{C}$ although the background intensity is high. The AES intensity of sul- fur remains constant between $200-500^{\circ} \mathrm{C}$. The coverage of sulfur is estimated to be about 0.82 monolayers. The sulfur is desorbed at about $550^{\circ} \mathrm{C}$ where the LEED pattern was changed into the facet-like one. The different surface reconstructions $(1 \times 1-\mathrm{S}$ and $2 \times 2-\mathrm{S})$ on the sulfurtreated III-V compound semiconductor (111) surfaces are discussed in terms of the bond strength between cation and anion.
[1] W. Mönch, Semiconductor Surfaces and Interfaces (Springer-Verlag, Berlin, 2001).

[2] S. Y. Tong, G. Xu, and W. N. Mei, Phys. Rev. Lett. 52, 1693 (1984).

[3] C. H. Li, Y. Sun, D. C. Law, S. B. Visbeck, and R. F. Hicks, Phys. Rev. B 68, 085320 (2003).

[4] D. J. Chadi, Phys. Rev. Lett. 52, 1911 (1984).

[5] K. W. Haberern and M. D. Pashley, Phys. Rev. B 41, 3226 (1990).

[6] A. J. Van Bommel and J. E. Crombeen, Surf. Sci. 93, 383 (1980).

[7] G. Xu, W. Y. Hu, M. W. Puga, S. Y. Tong, J. L. Yeh, S. R. Wang, and B. W. Lee, Phys. Rev. B 32, 8473 (1985).

[8] C. J. Sandroff, R. N. Nottenburg, J. C. Bischoff, and R. Bhat, Appl. Phys. Lett. 51, 33 (1987).

[9] J. Fan, H. Oigawa, and Y. Nannichi, Jpn. J. Appl. Phys. 27, L1331 (1988); ibid. 27, L2125 (1988).

[10] T. Ohno, Phys. Rev. B 44, 6306 (1991).

[11] B. Murphy, P. Moriarty, L. Roberts, T. Cafolla, G. Hughes, L. Koenders, and P. Bailey, Surf. Sci. 317, 73 (1994).

[12] M. Sugiyama, S. Maeyama, and M. Oshima, Phys. Rev. B 48, 11037 (1993).

[13] S. Ichikawa, N. Sanada, N. Utsumi, and Y. Fukuda, J. Appl. Phys. 84, 3658 (1998).

[14] S. Ichikawa, N. Sanada, S. Mochizuki, Y. Esaki, Y. Fukuda, M. Shimomura, T. Abukawa, and S. Kono, Phys. Rev. B 61, 12982 (2000).

[15] S. Ichikawa, N. Sanada, M. Shimomura, T. Abukawa, S. Kono, and Y. Fukuda, Surf. Sci. 454-456, 509 (2000).

[16] M. Shimomura, Y. Sano, N. Sanada, L. L. Cao, and Y. Fukuda, Appl. Surf. Sci. 244, 153 (2005).
[17] M. B. Lebedev, M. Shimomura, and Y. Fukuda, Semiconductors (in Russian) 41, 539 (2007).

[18] C. R. Bayliss and D. L. Kirk, J. Phys. D: Appl. Phys. 9, 233 (1976).

[19] J. M. C. Thornton, P. Unsworth, M. D. Jackson, P. Weightman, and D. A. Woolf, Surf. Sci. 316, 231 (1994).

[20] T. Eguchi, T. Miura, S. P. Cho, T. kadahira, N. Naruse, and T. Osaka, Surf. Sci. 514, 343 (2002).

[21] N. Sanada, M. Shimomura, Y. Fukuda, and T. Sato, Appl. Phys. Lett. 67, 1432 (1995).

[22] M. Naitoh, A. Watanabe, A. Konishi, and S. Nishigaki, Jpn. J. Appl. Phys. 35, 4789 (1996).

[23] N. Sanada, S. Mochizuki, S. Ichikawa, N. Utsumi, M. Shimomura, G. Kaneda, A. Takeuti, Y. Suzuki, Y. Fukuda, S. Tanaka, and M. Kamata, Surf. Sci. 419, 120 (1999).

[24] K.Lüdge, P. Vogt, O. Pulci, N. Esser, F. Bechstedt, and W. Richter, Phys. Rev. B 62, 11046 (2000).

[25] L.Töben, T. Hannappel, K. Möller, H.-J. Crawack, C. Pettenkofer, and F. Willig, Surf. Sci. 494, L755 (2001).

[26] M. P. Seah and W. A. Dench, Surf. Interface Anal. 1, 2 (1979).

[27] D. Briggs, M. P. Seah, Practical Surface Analysis, vol.1 Auger and X-ray photoelectron Spectroscopy, 2nd Edition (John Wiley \& Sons, 1983).

[28] L. E. Davis, N. C. MacDonald, P. W. Palmberg, G. E. Rianch, and R. E. Weber, Handbook of Auger Electron Spectroscopy, 2nd Edition (Phys. Elect. Ind. Inc., Minnesota, 1976).

[29] D. R. Lide, CRC Hand book of Chemistry and Physics, 84th Edition (CRC Press, 2003). 